\title{
A ESCOLA NA CIDADE E A ESCOLA NA ALDEIA: A CRIAÇÃO DO COLÉGIO ESTADUAL INDÍGENA BENEDITO ROKAG, TERRA INDÍGENA KAINGANG APUCARANINHA (TAMARANA/PR)
}

\author{
FLOR MAGALI LÓPEZ AGUILAR ${ }^{1}$ \\ UFSCar
}

LUIZ ANTONIO NORDER ${ }^{2}$

UFSCar

\begin{abstract}
RESUMO: Este texto analisa as interpretações da população kaingang da Terra Indígena Apucaraninha (Tamarana/PR) sobre a criação do Colégio Estadual Indígena Benedito Rokag, situado no interior da aldeia, e realiza uma comparação com o período anterior, quando os indígenas se deslocavam até a sede do distrito mais próximo para cursar o ensino médio. A revisão bibliográfica, a entrevista semiestruturada e a observação direta foram os instrumentos utilizados para a coleta e análises de dados. Os resultados da pesquisa de campo indicaram as principais dificuldades dos alunos indígenas para cursar o ensino médio em um distrito rural no entorno da Terra Indígena, entre as quais se destaca o preconceito, e também os principais benefícios e desafios associados à implementação do Colégio no interior da aldeia, com destaque para a importância da escola para a (re)construção da identidade social e cultural dos jovens indígenas.
\end{abstract}

PALAVRAS-CHAVE: educação escolar indígena; ensino médio; identidade; movimento indígena; discriminação.

ABSTRACT: This work analyzes the interpretations of the Kaingang population of the Apucaraninha Indigenour Land (Tamarana/PR) about the implementation of the Benedito Rokag Public School and makes a comparison with the previous period, when they had to follow up their secondary studies in a school located in the nearest district. Literature review, semi-structured interviews and direct observation were the instruments used for data collection and analysis. Field research results indicated the main difficulties of indigenous students to study in high schools in a nearby rural district, mainly the prejudice, as well as the key benefits and challenges associated with the implementation of the school inside the indigenous land. It is underlined the importance of school in the indigenous land for (re)construction of social and cultural identity of youth.

\footnotetext{
1 Possui graduação em Engenharia em Desenvolvimento Comunitário pelo Instituto Tecnológico de Comitán, México (2013), mestrado em Agroecologia e Desenvolvimento Rural pela Universidade Federal de São Carlos (2016). Atualmente é doutoranda no programa de Ecologia e Recursos Naturais pela Universidade Federal de São Carlos. E-mail: magaliaguilar_91@hotmail.com .

2 Professor do Programa de Pós-Graduação em Agroecologia e Desenvolvimento Rural da Universidade Federal de São Carlos (PPGADR/UFSCar). E-mail: luiz.norder@cca.ufscar.br .
} 
KEYWORDS: formal indigenous education; secondary school; identity; indigenous movement; discrimination.

\section{Introdução}

Nos últimos anos, tem sido crescente o debate científico e político sobre os processos de escolarização junto às comunidades indígenas. $O$ objetivo desta pesquisa é analisar como a população da Terra Indígena Apucaraninha interpreta a criação do Colégio Estadual Indígena Benedito Rokag no interior da aldeia, em comparação com o período anterior, quando os indígenas se deslocavam até o distrito mais próximo para ter acesso ao ensino médio.

As próximas seções apresentam uma revisão bibliográfica realizada por meio de consulta a documentos, pesquisas e legislação, visando uma contextualização histórica, social e educacional do Brasil e, particularmente, do estado do Paraná. A contextualização da colonização do Brasil permitiu a compressão dos processos de construção social e histórico entre os povos indígenas. No caso do Paraná, a realidade não é muito distinta, pois nele ocorreu um processo similar de territorilização e de dominação.

O item 5, intitulado $A$ escola na cidade e a escola na aldeia contém os resultados das entrevistas realizadas junto aos professores indígenas e não indígenas do colégio, bem como com lideranças, alunos atuais do ensino médio e alunos e ex-alunos que estudaram em uma escola pública de ensino médio localizada em um distrito rural próximo à aldeia. As entrevistas semiestruturadas foram realizadas com a intenção de conhecer a importância da escola de ensino médio para os moradores, as principais adversidades identificadas na escola da cidade e algumas demandas de professores e alunos na busca por um ensino diferenciado na constituição da escola no interior da aldeia.

\section{Povos indígenas no Brasil}


A história dos indígenas no Brasil no século XVI se caracterizou pela legalização do trabalho escravo indígena, no qual os indígenas trabalhavam nas roças, plantações ou fazendas dos colonizadores, de forma associada a um processo de catequização e dominação política e territorial (SUCHANEK, 2012; FREIRE e MALHEIROS, 2010). Segundo Apolinário (2013), a perda de territórios implicava a fragmentação do indivíduo, pois estes tornavam-se distanciados de seus espaços e recursos naturais, com os quais se relacionavam, dialogavam e através dos quais se alimentavam, sendo obrigados a resignificar suas referências culturais para manter sua identidade étnica pela injustiça vivida junto aos não indígenas.

Oliveira (1998) afirma que o processo de territorialização vivenciado pelos indígenas não pode ser entendido como uma via de mão única, já que sua utilização pelos indígenas conduz a uma construção de identidade étnica individualizada em relação ao conjunto genérico. O trabalho realizado por Darcy Ribeiro (1996) sobre a população indígena brasileira procurou fazer uma comparação sistemática sobre a situação em que se encontravam os grupos indígenas no século $X X$, considerando o grau de integração com a sociedade nacional e a conservação ou perda de autonomia cultural e linguística.

A tradição indigenista do Estado brasileiro foi marcada por um arbitrário controle social. Primeiramente, como enfatiza Ricardo (1995), a política de "atrair e pacificar" em nome da "integração dos índios à comunhão nacional", impunha aos indígenas seus nomes e respectivos chefes, a concentração espacial de populações, o que desconsiderava as diferentes identidades, línguas, tradições e, consequentemente, causava várias contaminações por doenças, além da implantação de sistemas paternalistas e precários de assistência social e confinamento territorial e exploração predatória dos recursos naturais.

Cunha (1995) apresenta um breve histórico sobre a questão indígena. No século XVI, os índios eram chamados de "bons selvagens", para uso na filosofia moral europeia, e de "abomináveis antropófagos", na colônia. Atualmente, as etnias apresentam menor diversidade sociocultural, incluindo as que resistiram ao processo de integração 
nacional ou aquelas ressurgidas a partir de mecanismos de reconstrução de identidade étnica. Os povos indígenas, por serem tradicionalmente agricultores, coletores e caçadores, estabelecem uma forte relação simbólica com a terra, razão pela qual um dos maiores conflitos no processo de colonização gira em torno exatamente das terras indígenas (TEIXEIRA, 2015). Alves (2007 apud CUNHA, 1987) analisa que no $16^{\circ}$ Congresso de Americanistas, realizado em Viena, em 1908, se deram as primeiras denúncias sobre os índios massacrados no Brasil devido a uma política nacional de extermínio.

Segundo dados do censo do Instituto Brasileiro de Geografia e Estatística (IBGE) e do Instituto Socioambiental (ISA), a população brasileira em 2010 contava com 190.755.799 de pessoas, das quais 817.963 eram indígenas, representando 305 diferentes etnias e 274 línguas nativas faladas. Segundo Cohn (2001), atualmente no Brasil se vive e se lembra a "explosão étnica", pois aqueles que negavam sua identidade indígena, seja por vergonha ou pela repressão da sociedade, hoje voltam a articular sua indianidade, (re)construindo signos de identidade indígena. Considera-se o respaldo da Constituição da República Federativa do Brasil, o reconhecimento das distintas culturas, línguas e o direito de possuir o território tradicionalmente ocupado.

No entanto, apesar das garantias constitucionais, a temática indígena tem sido bastante conflituosa ainda no século XXI; basta mencionar, entre vários outros exemplos, a violência recente contra indígenas em várias regiões do país, as diversas usinas hidroelétricas construídas nas reservas indígenas, como é o caso da Usina Hidrelétrica Belo Monte, na bacia do Rio Xingu, ou ainda a ameaça representada pela Proposta de emenda à Constituição 215, que tem como objetivo transferir para o Legislativo a demarcação de terras indígenas e a fixação de um marco temporal para definir o que são as terras indígenas. Assim, uma vez mais os indígenas do Brasil enfrentam expressivas adversidades sociais e políticas.

\section{Breve histórico da educação indígena no Brasil}


A evolução da instituição escolar no Brasil do século XVI se expressa na criação de colégios de base religiosa, considerados como um meio para garantir aos jovens clérigos uma vida produtiva e honesta; posteriormente, passou a ser considerado uma condição imprescindível para uma boa educação. Além de desenvolver um sistema disciplinar rigoroso, havia uma vigilância constante, a delação institucional erigida como princípio de administração, além da ampla aplicação de castigos corporais (ARIÈS, 1978).

Segundo Albuquerque (2007 e 2009), os colonizadores e os missionários partilhavam da noção de que os indígenas eram bárbaros e precisavam ser civilizados e catequizados. Diante disso, as crianças e jovens indígenas iam para as escolas de internato, nas quais, além da violência física, existia uma violência cognitiva, forçando-os ao desprezo de si mesmos e à negação de sua identidade. A educação fomentada por esta instituição era fundada na "pacificação" dos índios autônomos ou dos "semisselvagens" para que se covertessem em "índios semicivilizados"; com isto, seriam inseridos, sobretudo, nos trabalhos da agricultura e da pecuária. No processo de educação escolar, os índios aprendiam a língua portuguesa e recebiam treinamento para a realização de trocas comerciais.

Da mesma maneira, Tassinari (2008) descreve as ações "educativas" feitas pelo Serviço de Proteção aos Índios e Localização de Trabalhadores Nacionais (SPILTN) a partir de 1910. A primeira fase era de "pacificação", que consistia num processo de sedentarização; a segunda, de "educação", com a implantação de escolas nas quais se ensinava matemática para comércio, técnicas agrícolas, pecuárias e industriais; na terceira, desenvolviam-se ações para a "civilização", quando os indígenas entravam no mercado de trabalho nacional; e, finalmente, a quarta fase, de plena introdução dos indígenas na "vida civilizatória".

A educação escolar indígena foi reestabelecida na Constituição da República Federativa do Brasil de 1988, que passou a definir que o Estado deve garantir conteúdos mínimos para assegurar a formação básica, além de fornecer o ensino fundamental na língua portuguesa e também, simultaneamente, em suas línguas maternas. O Decreto 26, de 4 de fevereiro de 1991, transferiu para o Ministério de Educação (MEC) 
as responsabilidades educacionais até então atribuídas à Fundação Nacional do Índio (Funai), devido às petições e reivindicações do movimento indígena. Em 1992 foi instituído no MEC o Comitê de Educação Escolar Indígena, com a finalidade de apoiar e subsidiar ações do programa da educação escolar indígena (SILVA, 1994).

O Ministério de Educação tornou-se desde então o responsável pela coordenação das ações escolares de educação indígena, sendo que sua execução deve ser garantida pelos estados e municípios, por meio da educação bilíngue, adequada às peculiaridades culturais dos diferentes grupos, preferencialmente através de professores indígenas. A formação inicial destes deve ocorrer em serviço e concomitante à sua própria escolarização; com isso, preconiza-se que os professores elaborem currículos e programas específicos para as escolas onde atuam, com o desenvolvimento de metodologias específicas e ensino de segundas línguas; uso e estabelecimento de um sistema ortográfico para as línguas maternas; incorporação de saberes tradicionais; elaboração de materiais didáticos-pedagógicos, entre outros aspectos.

Entre os dispositivos normativos que garantem a participação das comunidades indígenas se encontra a Lei de Diretrizes e Bases da Educação Nacional, de 09 de janeiro de 2001, e o Plano Nacional de Educação (PNE), que estabelece a especificidade dos modelos de educação intercultural bilíngue por meio da criação da categoria de escola indígena. Entre seus objetivos estão o da universalização, em dez anos, da oferta às comunidades indígenas de programas educacionais equivalentes às quatro primeiras séries do ensino fundamental, respeitando seus modos de vida, suas visões de mundo e as situações sociolinguísticas específicas; a ampliação gradativa da oferta de ensino de $5^{\mathrm{a}}$ a $8^{\mathrm{a}}$ série à população indígena; a criação, tanto no Ministério da Educação como nos órgãos estaduais de educação, de programas voltados à produção e publicação de materiais didáticos e pedagógicos específicos; a promoção da correta e ampla informação para a população brasileira em geral sobre as sociedades e culturas indígenas, como meio de se combater o desconhecimento, a intolerância e o preconceito em relação a essas populações (PLANO NACIONAL DE EDUCAÇÃO, 2001). 
Segundo Cohn (2014), nos dias de hoje é impossível "levantar uma aldeia sem escola". Assim, há um amplo reconhecimento da importância e do impacto das escolas no interior das aldeias, seja econômico (geração de renda e criação de postos de trabalho), político (formação de lideranças, debate sobre a representatividade em mecanismos de controle social) ou cultural, como também na geração de pedagogias próprias; no entanto, pode apresentar risco de desvalorização de suas culturas.

Por outro lado, Gallois (2014) argumenta que há uma contradição inerente à escola: por um lado, atua como um instrumento de empoderamento para conquistar a autonomia, no qual os indígenas tomam as instituições escolares para fazer delas um espaço para o exercício da política; por outro, representa uma armadilha para a domesticação de conhecimentos. Albuquerque (2007) interpreta a educação indígena como resultado do movimento nacional e reinvindicações locais: embora as escolas sejam diferentes, existe entre elas um objetivo em comum, e este é a reformulação do processo de educação escolar e desenvolvimento de sistemas de ensino que devem atender às expectativas das comunidades indígenas em relação à escola. Há, portanto, um importante e atual debate teórico, interpretativo e político sobre a presença de escolas nas terras indígenas.

A educação escolar indígena atualmente no Brasil é mais que um processo educativo, é uma constante reinvindicação pela educação escolar indígena, embora os resultados sejam até certo ponto favoráveis, a falta de estruturas pedagógicas educacionais próprias, ou seja, que a organização se dê por meio dos territórios etnoeducacionais. Existe a necessidade, no Paraná, de atender as demandas de formação de professores, melhorias nas escolas, elaboração de projetos políticopedagógicos pelos professores ou pela comunidade.

No Brasil, a pobreza e a desigualdade têm gênero, cor, historicidade e classe social. Por isso que as ações afirmativas são medidas especiais para eliminar as desigualdades acumuladas historicamente na sociedade. No entanto, quando se questiona sobre o acesso dos indígenas ao ensino superior, o déficit ainda é grande, pois, segundo dados de ANDIFES (2011 apud PANKARARU, 2012), 54\% dos estudantes de universidades federais são brancos, enquanto os 
estudantes indígenas representam apenas 0,9\%. Atualmente no Brasil há vinte universidades públicas que oferecem cursos de licenciatura intercultural, nos quais 524 professores indígenas se formaram e outros 2953 estão em fase de formação.

Mato (2009) descreve o panorama das experiências de educação superior dedicadas a atender as necessidades e demandas da educação superior das comunidades dos povos indígenas e afrodescendentes na América Latina. O autor apresenta as principais funções dos arranjos interinstitucionais orientados para oferecer oportunidades de formação indígena no ensino superior.

A ampliação e as primeiras experiências de ações afirmativas voltadas para o acesso ao ensino superior no Brasil remontam ao início da década de 1990, por meio de convênios entre a Funai e algumas universidades públicas e privadas, como a Universidade Federal do Amazonas (UFAM) e a Pontifícia Universidade Católica de Goiás (PUC$\mathrm{GO}$ ). As cotas passam a ser uma opção político-ideológica da sociedade brasileira (LUCIANO, 2006).

O estado do Paraná foi o primeiro do Brasil a instituir o Vestibular dos Povos Indígenas em universidades públicas, pois a Assembleia Legislativa do Paraná publicou em 2001 a Lei 13.134, que destinou três vagas por ano em cada uma das universidades estaduais exclusivamente para candidatos pertencentes às etnias indígenas que residiam ou residiram no mínimo dois anos nas terras indígenas demarcadas no estado do Paraná. Em 2006, devido à crescente demanda dos indígenas, foi aprovada a Lei 14.995, que aumentou o número de vagas por instituição estadual para seis. Ao longo de quatorze anos, no meio de incontáveis experiências, de erros e acertos, as universidades, por meio de um processo de seletivo específico, dão oportunidade aos indígenas de terem acesso ao ensino superior.

Amaral e Faria (2012) afirmam que a permanência dos estudantes indígenas na universidade é possível mediante a efetivação de um duplo pertencimento, ou seja, acadêmico e étnico-comunitário - entende-se por pertencimento étnico-comunitário todas as relações afetivas, culturais, econômicas e políticas estabelecidas entre os estudantes indígenas e os membros de sua parentela. Quanto à permanência, Paulino (2008) descreve os principais problemas enfrentados pelos 
estudantes indígenas nas universidades: o valor insuficiente da bolsa de estudos para custear a moradia, alimentação, custos com a formação e despesas pessoais.

\section{Povos indígenas e educação no Paraná}

De acordo com Tommasino (2001), os povos indígenas no estado do Paraná do século XVI e XVII eram os Tupi, que habitavam litoral. No século XVI, os Guarani ocupavam a maior parte do estado. No entanto, com a chegada dos jesuítas espanhóis, que tinham como objetivo catequizar os índios, foram fundadas treze reduções distribuídas nas bacias dos rios Paraná, Tibagi, Piquiri, Ivaí e Iguaçu. Porém, essas reduções foram destruídas pelos bandeirantes paulistas, que levaram os indígenas como escravos para São Paulo. Os Guarani tornaram-se o grupo majoritário no norte do Paraná. Esse panorama muda no século XVIII, quando os Kaingang tornam-se o grupo majoritário na região.

Em Portugal, o termo "aldeia" era utilizado para designar o habitat rural com concentração de moradias, enquanto no Brasil o nome "aldeamento" significava a aglomeração de indígenas até então dispersos em um local mais concentrado; remetia, portanto, a uma espécie de "intervenção" colonizadora na organização espacial dos indígenas. Não era, portanto, a ocupação "original" do território. No caso dos Guarani, as aldeias eram chamadas tehoka; os Kaingang as chamavam de emã. No início do século XVII, nas vilas espanholas, em Ciudad Real, por exemplo, predominava a "intenção objetiva" de agrupar as populações indígenas para inculcar os valores das sociedades conquistadas.

No entanto, destruídas as reduções pelos bandeirantes e o abandono da vila espanhola, o território passou a ser ocupado pelos Guarani, pelos Xetá e pelos Jê do Sul - Kaingang e Xoclengue (PARANÁ, 2009). Como parte do acosso dos portugueses, que procuravam escravizar aos índios para trabalhar na mineração ou para vendê-los em São Paulo, os Kaingang que viviam nos séculos XVI-XVII próximos à Serra do Mar se refugiaram ao longo da Serra Geral, no oeste. Os 
Kaingang do Paraná se fixaram nas regiões onde antes se localizavam as reduções jesuíticas (TOMMASINO, 2002).

A bacia do Rio Tibagi, na porção norte do Paraná, tem sido um território ocupado por populações indígenas desde tempos imemoráveis, mas também, historicamente, como campo de batalha entre colonizadores e populações indígenas. Nos séculos XVI, XVII e $\mathrm{XVIII}$, as conquistas dos territórios paranaenses eram justificadas em nome do "Rei" (Espanha ou Portugal) e de "Deus". No século XIX, a usurpação e conquista de terras no Paraná ocorreram em nome da "Nação Brasileira". No século XX, a justificativa passou a ser 0 "Progresso", destituindo os remanescentes territórios kaingang, para transformá-los em áreas agrícolas; no final do século, há importantes interações e embates com a Companhia Elétrica de Paraná (Copel) (MOTA, 1996).

As etnias indígenas que habitam atualmente o estado de Paraná são: Guarani, Kaingang e Xetá. A economia baseia-se na produção de roças de subsistência e pomares, na criação de galinhas e porcos, como também na produção e venda de artesanato (cestos, balaios, arcos e flechas), nas políticas sociais (Bolsa Família, cesta básica, agentes de saúde) e no assalariamento. Os Guarani dividem-se em três subgrupos: Mbyá, Nhandéva e Kaiová. Vale lembrar que os povos Guarani, de uma forma geral, têm preservado sua identidade através de sua cultura e língua, abrangendo grandes territórios: Brasil, Argentina, Uruguai e Paraguai (VANALI, 2003).

Parte da construção da identidade étnica guarani se organiza em oposição à do kaingang. Os Guarani falam uma língua tupi, pertencente à família Tupi-Guarani. No Paraná vivem três grupos dialetais Guarani: os Nhandéva (Ñhandéva; Chiripá), os Kaiová (Kayoá; Kaiwá; Kaiowá) e os Mbyá (Mbüá; Mbiá). Na região norte do estado vivem grupos Nhandéva e Kaiová (TOMMASINO, 1992). Os Kaingang falam uma língua filiada à família Jê, representando mais de $40 \%$ do total dos povos de língua jê no Brasil. Desenvolveram uma adaptação altamente especializada aos cerrados e cocais, embora baseassem sua subsistência principalmente na caça e na coleta (LEVI-STRAUSS, 2014; RIBEIRO, 1996; D'ANGELIS e VEIGA, 2003). 
Os Xetá habitam o centro-sul do Paraná e pertencem ao tronco linguístico Tupi-Guarani. As primeiras notícias sobre esta etnia foram divulgadas em 1940, na Serra dos Dourados, região noroeste do Paraná. O povo Xetá foi vítima do extermínio durante a expansão cafeeira. No entanto, sobreviveram alguns indivíduos (crianças e jovens), desapropriados de seu território por fazendeiros ou por funcionários do antigo Serviço de Proteção aos Índios (SPI) na década de 1950, e também retirados de seus familiares e de seu referencial cultural para serem criados por famílias brancas que habitavam diferentes pontos do Paraná (ALMEIDA e DOS SANTOS, 2011; BUZATTO, PELIZZARI e BUZATTO, 2015).

O processo de ocupação do território indígena no Paraná afigurase como uma trágica história para a sobrevivência de suas etnias indígenas. Na visão do colonizador, na região havia um "vazio demográfico", ou seja, uma ausência de reconhecimento da existência das populações indígenas. Além da ocupação das terras, a classe dominante apagou a história dos povos indígenas, ignorando sua luta, sua resistência, seu modo de viver e sua identidade para convertê-los, no melhor dos casos, em trabalhadores rurais assalariados (MOTA, 2008).

As políticas indigenistas no Paraná, assim como no restante do país, tinham o objetivo central de expropriar as terras ocupadas ancestralmente pelos indígenas. Na segunda metade do século XIX, os interesses da sociedade "paranaense" determinavam as áreas a serem ocupadas. Assim, os territórios pertencentes aos povos indígenas foram conquistados e ocupados. A historiografia oficial ignorou acontecimentos importantes de luta e resistência dos índios que enfrentaram os invasores para manter seu espaço e modo de vida. A interpretação de que esses territórios eram "vazios" e que poderiam ser ocupados foi recusada em 1854 através do Decreto 1.318, que regulamentou a Lei de Terras e encarregava as Comissões Provinciais de demarcarem as terras dos Aldeamentos Indígenas (VANALI, 2013).

$\mathrm{Na}$ segunda metade do século XIX, o governo imperial contratou frades capuchinhos italianos para implementar este projeto (VANALI, 2013). Darcy Ribeiro (1996) descreve outro tipo de extermínio dos indígenas no processo de aquisição de terras nos estados de São Paulo, 
no sul de Minas Gerais e norte do Paraná, devido à "onda verde" representada pela cafeicultura. Nos primeiros anos, a fronteira alcançava contra as florestas que se estendiam do Vale do Tietê ao Vale do Paranapanema, e dali ao Paraná.

O avanço para novas regiões do norte do Paraná foi justificado pela ampliação da área cafeeira. O apogeu deste processo ocorreu no período do pós-guerra (1945-1971). Nas décadas de 1940 e 1970, o café gerou milhares de empregos e impulsionou a economia da região, sobretudo nos municípios de Londrina, Apucarana e Maringá. A plantação de café propiciou significativas mudanças socioeconômicas, políticas e demográficas no norte do Paraná e transformou os supostos "vazios demográficos" em regiões agrícolas ou urbanizadas (OLIVEIRA, 2009). A apropriação das terras "devolutas ora desabitadas ora selvagens" teve a finalidade de viabilizar a expansão da produção cafeeira.

Os aldeamentos indígenas do século XX no Paraná foram marcados também, como outros territórios indígenas, pela evangelização, pois a educação não era bilíngue, e os professores não eram indígenas. $O$ objetivo da escola não era a conquista da autonomia socioeconômica e cultural, a recuperação de sua memória histórica, a reafirmação da identidade étnica ou valorização da própria língua e etnoconhecimentos (TOMMASINO, 2003).

A educação indígena não é própria ou restrita da instituição ou do ambiente escolar, mas é um elemento próprio da cultura kaingang, pois as estruturas e pedagogias educacionais próprias se regulam de acordo com os princípios e a organização pautados na cosmovisão e cosmologia kaingang. Assim, a educação é concebida na dinâmica de socialização; por exemplo: a rotina e o cotidiano das crianças, ponto referencial para a percepção da cultura no espaço e no tempo, nas palavras de Nunes (2009, p. 69), "obedece a esquemas rigorosos de construção e transmissão de saberes, e é desse modo que as crianças os incorporam e deles vão tomando consciência" (apud LUCKMAN, 2011, p. 24).

No estado do Paraná, a Secretaria de Estado da Educação estabelece, por meio do Decreto 6.861/2009, a liberdade da educação escolar indígena, na definição de sua organização em territórios 
etnoeducacionais. A Secretaria de Educação Profissional e Tecnológica do Ministério da Educação afirma que a demanda atual dos indígenas no âmbito profissional consiste na busca por uma formação que possa ter uma relação entre conhecimentos e práticas indígenas e conhecimentos técnico-científicos. Assim, a educação indígena envolve uma série de fatores cruciais, entre os quais se destacam os princípios e direitos da educação escolar indígena: o respeito à sociodiversidade, a interculturalidade, o direito de uso de suas línguas maternas e de processos próprios de aprendizagem, a articulação entre os saberes indígenas e os conhecimentos técnico-científicos, entre outros aspectos. A formação integral na educação profissional técnica visa a atuação cidadã no mundo do trabalho, a sustentabilidade socioambiental e o respeito à diversidade dos sujeitos.

O estudo realizado por Tommasino (2003) sobre as diretrizes para a política de educação escolar indígena no Paraná evidencia os problemas mais comuns da educação nas reservas indígenas. A autora afirma que esses problemas estão relacionados com a natureza da educação e do modelo pedagógico, pois a política indigenista continua direcionada para a integração do índio ao sistema nacional, pelo que os projetos ainda seguem com o "mesmo modelo integracionista do século $\mathrm{XVl}$ ".

\section{A educação na Terra Indígena Apucaraninha}

A Terra Indígena Apucaraninha localiza-se no sudoeste do município de Londrina, sendo limitada ao norte pelo Rio Apucaraninha, ao sul pelo Rio Apucarana, ao leste pelo Rio Tibagi e ao oeste por algumas estradas, represas e cortes aleatórios entre as latitudes $23^{\circ} 44^{\prime} 00^{\prime \prime}$ S e $23^{\circ} 52^{\prime} 00^{\prime \prime}$ S e longitude $50^{\circ} 52^{\prime} 00^{\prime \prime} \mathrm{O}$ e o $50^{\circ} 59^{\prime} 00^{\prime \prime} \mathrm{O}$. A Terra Indígena ( $\mathrm{TI})$ foi criada pelo Decreto Estadual 6, de 5 de julho de 1900, inicialmente com o nome de Posto Dr. Xavier da Silva, então governador do estado de Paraná; depois foi alterado para Posto Indígena Apucarana, abrangendo uma área de 80 mil hectares. Devido a um acordo entre o Ministério da Agricultura e o Governo do Estado do Paraná, em dezembro de 1949, a área foi reduzida para 6.300 hectares, 
utilizando o critério de 100 hectares para cada família e 500 hectares para a sede do Posto. Atualmente, a Terra Indígena compreende uma área aproximada de 5.640 hectares, estando incógnitos 660 hectares, em virtude da prevalência de antigas invasões por parte de fazendeiros (LONDRINA, 2016).

Neste território está instalada uma usina hidrelétrica, atualmente sob a responsabilidade da Companhia Paranaense de Energia (Copel) empresa mista estadual, criada em outubro de 1954, que atua com geração, transmissão e distribuição de energia, além de telecomunicações. A usina foi construída para abastecer principalmente o município de Londrina. A construção teve início em 1946, entrando em operação em 1949. A usina funciona com o aproveitamento do Salto Grande, com 125 metros de altura, no Rio Apucaraninha. Dois reservatórios fazem parte do projeto, sendo o menor chamado de Apucaraninha, com um milhão de metros cúbicos, a cerca de um quilômetro da aldeia Sede. E o outro, de regularização, a montante do primeiro, denominado de Fiú, com 15 milhões de metros cúbicos, a cerca de cinco quilômetros da Aldeia Sede (CIMBALUK, 2013).

A população da Terra Indígena Apucaraninha atualmente é de aproximadamente 1.300 pessoas, em um total de 350 famílias. A maior parte da população concentra-se na aldeia Sede. A Terra Indígena Apucaraninha divide-se em quatro agrupamentos: Sede, Barreiro, Água Branca e Serrinha. Na aldeia Sede, há um posto de saúde, que conta com um médico (nacionalidade cubana) e uma enfermeira, realizando atendimento permanente à população indígena e, em alguns casos, com cota para aqueles que não são indígenas. Há também um salão de baile, Venh Kar, a Escola Estadual Indígena João Kavagtan Vergílio (nome indígena: Aoãokavag Tãnvirgilio), inaugurada em 1982, e o Colégio Estadual Indígena Benedito Rokag. A aldeia conta com energia elétrica e água encanada. A maioria das residências é de alvenaria, construídas no âmbito de um programa do estado do Paraná, implementado em 2003.

A aldeia Barreiro foi criada nas décadas de 1950 e 1960, segundo alguns moradores. Conta com a Escola Estadual Indígena Roseno Vokrig Cardoso, onde atuam quatro professores, duas auxiliares de serviços gerais e um diretor não indígena, contratados pelo Governo do Estado do Paraná, e com um posto de saúde, apenas com serviço de 
enfermagem, também com energia elétrica e água encanada. Caracteriza-se por plantações em áreas distantes das casas. A aldeia Serrinha foi criada em 2010, onde atualmente residem 12 famílias.

Com a Resolução 2.075/2008, publicado no Diário Oficial do Estado em 29 de maio de 2008, foram regulamentados a organização e o funcionamento das escolas indígenas no Sistema de Ensino do Estado do Paraná. Os estabelecimentos de ensino que funcionavam em terras habitadas por comunidades indígenas passaram a ser reconhecidos como escolas da rede estadual e identificadas como "escola estadual indígena", independentemente do nível ou modalidade de ensino. Dessa maneira, foram reconhecidas três escolas na TI Apucaraninha.

A Escola Estadual Indígena João Kavagtan Vergílio está localizada na aldeia Sede, na Terra Indígena Apucaraninha, tendo sido inaugurada em 1982, inicialmente denominada Escola Cacique Luiz Pênki Pereira. Em 2015, havia 17 professores indígenas e uma professora não indígena, que residia na aldeia. Cabe destacar que a escola participou de um programa nacional desenvolvido pela Funai cujo objetivo era o de ampliar o acesso dos indígenas à educação básica. A Prefeitura do Município de Londrina e o Governo do Estado do Paraná eram os encarregados pela destinação dos recursos para a escola. No entanto, a partir de 23 de maio de 2008, a Secretaria de Estado da Educação publicou a Resolução 20.75/2008, que estabeleceu um acordo para que a Escola fosse organizada e recebesse assistência por meio do Sistema de Ensino do Estado do Paraná. Desta maneira, o estado do Paraná se tornou responsável direto pelo ensino, manutenção e pela formação dos professores indígenas desta escola. Nas primeiras séries da educação (Pré-Escola e Ensino Fundamental I), as crianças são monolíngues: unicamente falam a língua kaingang e começam a ser alfabetizadas por meio da língua kaingang; o ensino da língua portuguesa começa a ser introduzido a partir da $3^{a}$ série.

A Escola Estadual Indígena João Kavagtan Vergílio localiza-se na aldeia Sede da TI Apucaraninha. Atende a Pré-Escola e o Ensino Fundamental I, séries iniciais da Educação Básica. A Escola Estadual Indígena Roseno Vokrig Cardoso localiza-se na aldeia Barreiro e oferece Pré-Escola e Ensino Fundamental I, séries iniciais da educação básica (Tabela 1). 
Apresenta-se, na Tabela 1, o número total de matrículas dos três últimos anos nas escolas da Terra Indígena Apucaraninha:

Tabela 1 - Número total de matrículas dos últimos três anos nas escolas da TI Apucaraninha (2013 - 2015).

\begin{tabular}{|l|c|c|c|c|c|c|c|c|c|}
\hline \multicolumn{9}{|c|}{$\begin{array}{c}\text { Número total de matrículas dos últimos três anos } \\
\text { nas escolas da TI Apucaraninha (2013 - 2015) }\end{array}$} \\
\hline & \multicolumn{3}{|c|}{ Pré-escola } & \multicolumn{2}{c|}{ Ensino fundamental } & \multicolumn{3}{c|}{ Ensino médio } \\
\hline & 2013 & 2014 & 2015 & 2013 & 2014 & 2015 & 2013 & 2014 & 2015 \\
\hline E.E.I.J.K.V.* & ---- & 30 & 15 & ---- & 201 & 189 & ---- & ---- & ---- \\
\hline E.E.I.R.V.C.* & ---- & ---- & 2 & ---- & 13 & 11 & ---- & --- & ---- \\
\hline C.E.I.B.R.* & ----- & ----- & ---- & 184 & 170 & 138 & 27 & 37 & 40 \\
\hline TOTAL & ---- & $\mathbf{3 0}$ & $\mathbf{1 7}$ & $\mathbf{1 8 4}$ & $\mathbf{3 8 4}$ & $\mathbf{3 3 8}$ & $\mathbf{2 7}$ & $\mathbf{3 7}$ & $\mathbf{4 0}$ \\
\hline
\end{tabular}

* E.E.I.J.K.V.: Escola Estadual Indígena João Kavagtan Vergílio. E.E.I.R.V.C.: Escola Estadual Indígena Roseno Vokrig Cardoso. C.E.I.B.R.: Colégio Estadual Indígena Benedito Rokag.

Fonte: Adaptado pela autora a partir de dados da Secretaria de Estado da Educação do Paraná.

Em sua demanda por um sistema educacional diferenciado, os Kaingang da TI Apucaraninha, tendo em vista a deserção e as dificuldades para deslocar os alunos que estudavam na cidade, resolveram se organizar politicamente para conseguir a escola de ensino médio no interior da Terra Indígena; e em 2012 teve início a construção da escola por parte do governo estadual. Por outro lado, uma das primeiras professoras da escola relata sobre as adversidades que enfrentaram alguns professores devido à falta de transporte, como também a falta de professores, de merenda e de uma biblioteca:

Fui uma das primeiras professoras contratadas, eu, professora de sociologia, professor de geografia, educação física. Eram os únicos professores da escola. Então eu dormi na escola, já praticamente morei na escola. No começo não tinha transporte, então a gente vinha no carro de um professor [...]. Não estava completo: faltava professor de química, faltava professor de física, professor de inglês, a gente ficava dando várias aulas por dia, aulas que inclusive não era de nossas áreas, para que os alunos pudessem ter o quadro completo [...]. No começo não tinha merenda, não tinha biblioteca, mesmo assim a gente estava aqui (Larissa Rocha, professora de História no CEI Benedito Rokag, 2015). 
O CEI Benedito Rokag foi construída em um formato circular, contém um espaço externo com quadro, onde os alunos merendam, jogam pingue-pongue, convivem com alguns professores e demais estudantes. Há também uma sala para professores, outra para a direção, uma biblioteca e salas de aula. Além disso, há mesas e cadeiras de concreto com tabuleiros de xadrez e/ou damas. A escola ainda não possui quadra para aulas de educação física. Com isso, os professores optam por realizar as atividades correspondentes no campo de futebol da aldeia. Apesar da existência desta escola de ensino médio no interior da aldeia, alguns pais preferem que seus filhos estudem na escola localizada no distrito rural mais próximo, pois acreditam que o ensino é de melhor qualidade, e também porque, segundo eles, aprendem melhor a língua portuguesa (Figura 1).

Figura 1: Croquis do Colégio Estadual Indígena Benedito Rokag.

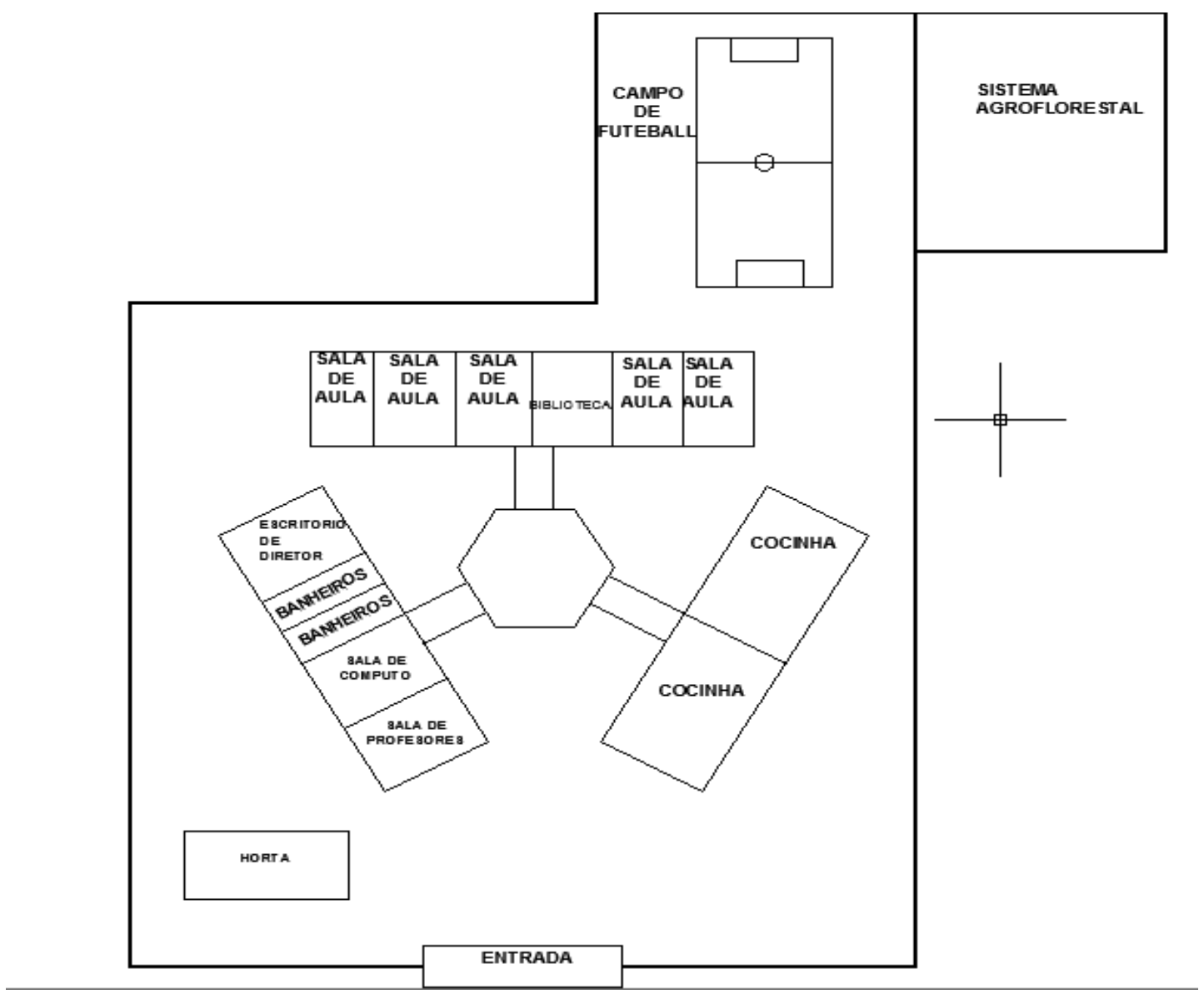

Fonte: Realizado pela autora. 


\section{A escola na cidade e a escola na aldeia}

Os indígenas kaingang expressaram as principais dificuldades de se estudar na cidade, entre as quais se destacam: a distância percorrida diariamente pelos estudantes, as adversidades climáticas, a discriminação, o desinteresse dos professores pela cultura indígena, o alto índice de reprovação, a deserção escolar. Tais adversidades, especialmente a deserção escolar indígena, devido ao trajeto para chegar à escola do distrito rural do entorno, são confirmadas em entrevista concedida pela pedagoga indígena Marilene Bandeira do CEI Benedito Rokag:

No começo do ano, no início do ano, sempre tinha bastante aluno; aí, quando ia chegando no final de ano, já havia bem pouquinho aluno; aí, esse pouquinho que conseguia fechar o ano, passar de ano, tinham muita dificuldade. A estrada era muito ruim também, a chuva, frio, eles enfrentavam. Aí, vendo tudo isso, as lideranças do Paraná se reuniram junto com o governo, não lembro qual época, qual governo também, né? Mas eles, com aquela luta que eles foram, eles conseguiram ter esse colégio na terra indígena; e a gente também percebia que os alunos sofriam muito lá fora, muito, sofriam muita discriminação, por ser indígena, por falar a língua, né? $\mathrm{Na}$ escola, os alunos discriminavam, professores discriminavam, né? Então, a gente vendo tudo isso, o sofrimento deles [...] (Marilene Bandeira, kaingang, pedagoga do CEI Benedito Rokag, 2015).

Para acrescentar o já falado pela diretora, o professor indígena kaingang Gabriel Kaje, morador da TI Apucaraninha dá seu testemunho sobre sua estadia na escola na cidade e as dificuldades de alguns jovens indígenas ao sair da aldeia para estudar na cidade:

Vou te dizer assim: no meu tempo que eu estive lá fora não era assim, era muito discriminado. Tem gente que está morando dentro da aldeia que são pobres humildes, eles não querem sair para estudar. Hoje pessoas daqui saem, nós temos uma cultura diferente [...] (Gabriel Kaje, professor indígena kaingang, 2015). 
Além disso, o professor Gabriel Kaje enfatiza a situação de discriminação e subestimação por parte dos não indígenas. Menciona também a importância da escola de ensino médio na aldeia, pois a mesma teria contribuído para reduzir a erosão da cultura e fortalecer a permanência próxima à família:

Eu vi, assim, muitas coisas, assim [...]. Porque nós
somos comunidade indígena, nós somos muito
discriminados pelos não indígenas. Muitas vezes
falaram assim: "índio não pode, não sei quê". É muita
discriminação. Eu, o que sempre digo: a aldeia
Apucaraninha, ele tem, eu vou dizer, ela tem uma coisa
assim de, para mim, seria um presente pra eles, tendo
uma escola ensino fundamental e ensino médio aqui
dentro da área indígena, porque minha preocupação
era que os indígenas novos que saem lá na cidade, que
levam discriminação e acabam desistindo de seu
estudo; e hoje ele fica mais perto da família, quando
acontece alguma coisa avisa. E essa escola para mim,
esse colégio que está tendo agora desde a reserva
indígena é de grande importância para mim, porque a
gente já tem tantas coisas aqui [...] (Gabriel Kaje,
professor indígena kaingang, 2015).

Também a professora indígena kaingang Gilda Kuitã, liderança que participou do processo de reinvindicação política pela educação indígena no Paraná, descreve a luta por uma escola diferenciada dentro da aldeia, devido às adversidades apresentadas pelos alunos indígenas em se trasladar para a escola na cidade e o nível de deserção e reprovação dos mesmos:

Porque o aluno terminava o quarto ano e ia estudar fora, aluno pequeno, que cresceu aqui, que só viveu aqui e logo estudou lá fora, e aí ele não continuava. Aí ele desistia, porque não dava certo, né? $\mathrm{E}$ aí por isso que a gente lutava, tem escola indígena, que deve ter professor indígena. Aí foi conseguindo, e a gente tinha reunião com o MEC no Brasil inteiro para mudar esse jeito de dar aula. Quando a gente conseguiu a escola, agora tem ensino médio, série inicial até ensino médio com professores que, assim, que tem capacidade de ensinar como a gente quer que seja (Gilda Kuitã, professora indígena kaingang de ensino inicial, 2015). 
Para corroborar o já exposto, os alunos expressam algumas das adversidades enfrentadas, como é o caso de Tiago de Almeida, que foi estudante na escola pública estadual próxima à Terra Indígena somente por um ano, ingressando posteriormente no CEI Benedito Rokag para continuar seus estudos. Entre os problemas que mencionou, estão a discriminação racial e a falta de interesse dos professores pela cultura indígena. Contudo, Tiago enfatiza a importância da escola diferenciada, devido ao uso de traços culturais kaingang abordados nas temáticas de sala de aula.

Problema que eu enfrentei [foi] a discriminação, a pessoa discrimina muito, tem pessoa que não se leva bem com nós por ser índio, tirando sarro da gente, fazendo aquela brincadeira de mau gosto com a gente. Aí que a gente enfrentou muito na cidade. Tipo assim, eles tentavam falar nossa língua, tirando sarro mesmo, tentando falar a nossa língua para zoar com nós, mesmo. A gente não gostava disso, mas a gente continua estudando. Até porque eles falam que nossa escola é diferenciada do que lá fora, porque todo ano a gente faz um evento cultural, que vale umas notas, tipo assim, só nossa cultura mesmo: arco e flecha, nossa comida, algumas coisas de indígenas, assim, para nós, daí já é diferenciado. Às vezes a gente vai para rio com os professores. Nunca ninguém mostrou interesse, só na despedida da gente, a gente conversou com o diretor para mostrar nossa cultura. Era só chegar lá, estudar e voltar (Tiago de Almeida, indígena kaingang, ex-aluno do CEI Benedito Rokag, 2015).

Outro ex-aluno do CEI Benedito Rokag, também ex-aluno do distrito rural, confirma a indiferença de alguns professores da escola fora da aldeia. No entanto, agora eles sentem maior confiança em estabelecer um diálogo com os professores do colégio da aldeia, pelo que existe uma maior compreensão dos conteúdos dentro das salas de aula.

Eu acho bom as crianças estudar, eu acho bom e daí os que ensinam aos alunos o que nós fazemos. Aí eles aprenderam dançar nossa dança, nossa dança cultural, essas coisas que as mulheres, as meninas que ensinam para eles. Só que tem alguns que não gostam, que não participam bem. É importante ensinar aos pequenos, aos mais velhos, eles estão aí, em nosso lugar, eu acho 
bom ensinar isso aí. Não foi bom [na cidade] igual aqui. É diferente, lá os professores não ensinam bem: a gente pergunta e eles não ensinam bem. Agora a gente quando não sabe de nada, só relaxa, conversa sobre trabalho, essas coisas. Lá não dá vontade de conversar com os professores, daí melhorou muito quando chegou o ensino médio (Indígena kaingang, ex-aluno do CEI Benedito Rokag, 2015).

Uma indígena kaingang que atualmente faz o curso de Psicologia na Universidade Federal de Paraná (UFPR), em Curitiba, enfatiza a importância de conhecer-se para poder pautar os direitos indígenas. Neste caso, a escola desenvolve um papel importante, pois por meio de uma educação específica pode-se revalorizar os traços culturais tradicionais entre a juventude.

\begin{abstract}
Empoderar a juventude nesse senso crítico, de você se empoderar do que é de lá fora e conhecer o nosso, porque nós precisamos nos conhecer, que é uma das coisas que a gente sempre discute, de que nós mesmos nos desconhecemos. Como que a gente vai pautar a questão dos direitos com as lideranças indígenas, com a juventude ou com a sociedade indígena em geral se nós mesmos desconhecemos nosso direito? Então a gente precisa trazer a escola, que vai fazer isso dentro da escola. Não se fala de uma educação específica, de um planejamento escolar específico, isso deve estar no planejamento escola. Então é aquilo que eu falei: não queremos reproduzir o que é de lá fora, senão vira branco, fazer o mesmo; então por que ter coisas específicas direcionadas aos povos indígenas? Por que ter uma saúde só para ter no papel, como está lá em cima? Então deve fazer valer (Jaciele Nyg, indígena kaingang, estudante de Psicologia na UFPR, 2015).
\end{abstract}

A escola, segundo Parente et al (2013, p. 169), contribui para o exercício dos direitos humanos, pois por meio de práticas pedagógicas em sala de aula se pode desconstruir estereótipos e preconceitos que sustentam práticas racistas e discriminatórias. Embora a escola contribua para a desconstrução de preconceitos, ainda continua sendo necessário ampliar significativamente os trabalhos de pesquisa, projetos pedagógicos, seminários e outras atividades visando o fortalecimento das práticas na escola. Nessa perspectiva, alguns moradores e alunos do CEI Benedito Rokag reconhecem sua identidade como sujeitos indígenas 
que valorizam o acesso à educação escolar. Além disso, ressalta-se a importância da autonomia para construir mecanismos pedagógicos alternativos que atendam às necessidades e visem empoderamento da juventude.

\section{Considerações finais}

O breve levantamento sobre a história da colonização do Brasil possibilitou a compreensão dos processos de territorilização e o recrutamento dos indígenas. Houve o impacto das políticas coloniais de tutelagem na redução dos territórios originais e um amplo processo de marginalização. Do mesmo modo, os colégios religiosos, com pedagogias baseadas na moralidade religiosa cristã, tinham a finalidade de evangelizar os indígenas e torná-los "civilizados". Desta forma, constatam-se as adversidades e a crueldade afrontada pelos "negros da terra" (indígenas) do Brasil.

As reflexões sobre os impactos das escolas no interior das terras indígenas precisam ser ampliadas. Em geral os estudantes indígenas que pretendem continuar estudando têm que se deslocar para as cidades ou distritos mais próximos. Contudo, os alunos enfrentam inúmeros desafios, econômicos, sociais e, especialmente, enfrentam o preconceito. Neste trabalho, vimos que a maioria dos jovens indígenas kaingang que pretendiam continuar seus estudos no ensino médio em um distrito rural no entorno apresentaram elevados índices de reprovação e, em muitos casos, acabaram por desistir da escola de ensino médio. Os resultados desta pesquisa mostram que a escola de ensino médio levou a significativas mudanças para os jovens indígenas que puderam estudar na própria aldeia, tendo em vista o tipo de interação com os professores, situação que não ocorria na escola de fora da aldeia, dado o temor ou vergonha. Tais aspectos não eram tão visíveis quando os alunos estudavam fora da aldeia. Pode-se observar uma reafirmação e valorização, ainda que não generalizada, da identidade kaingang na escola na aldeia.

O levantamento historiográfico sobre o estado do Paraná reforça a interpretação de que ocorreu um processo similar de territorialização, 
denominado "vazio demográfico", com o consequente desalojamento dos habitantes guarani, xetá e kaingang. Além disso, o histórico da educação escolar no Paraná possibilitou esclarecer as construções sócio-históricas e compreender como é concebida a educação escolar na dinâmica da socialização. Na atualidade, não há aldeia sem escola. No caso da Terra Indígena Apucaraninha, houve uma demanda da comunidade visando obter uma escola de ensino médio dentro da aldeia, o que está associado com a busca por um ensino diferenciado, ainda em construção, que valorize sua cultura, sua língua e reforce sua identidade cultural. Um ensino diferenciado kaingang, enfim.

Este estudo mostra a necessidade de realizar pesquisas e discussões associadas a reflexões teóricas e metodológicas aplicadas dentro da sala de aula, para reafirmar a identidade da juventude indígena e a aplicação do ensino diferenciado nas escolas indígenas. $O$ objeto pesquisado, o Colégio Estadual Indígena Benedito Rokag, além de ser valorizado pelos moradores da Terra Indígena Apucaraninha, requer atenção especial tanto em assessorias aos professores, indígenas ou não indígenas, como também na elaboração de material didático adaptado.

\section{Referências bibliográficas}

ALBUQUERQUE, Judith Gonçalves. Educação escola indígena: do panóptico a um espaço subjetivação na resistência. 2007. 259 f. Tese (Doutorado em Linguística) - DL, IEL, UNICAMP, Campinas, SP, [2007].

Resistência Tuyuka nas políticas de ensino da língua. In: SEMINÁRIO DE ESTUDOS EM ANÁLISE DO DISCURSO 1969-2009: MEMÓRIA E HISTÓRIA NA/DA ANÁliSE DO DISCURSO, 4. 2009, Porto Alegre. Anais... Porto Alegre, SEAD, UEMG, 2009.

ALMEIDA, Priscila Rosalen Pasetto; DOS SANTOS, Jaqueline. Povos indígenas no norte do Paraná. Londrina: UEL, 2011.

ALVES, Jean Paraiso. Em busca da cidadania: escolarização e reconhecimento de identidades indígenas em dois países Americanos (Brasil e México). 2007. 349 f. Tese (Doutorado em Ciências Sociais. Estudos comparados sobre as Américas) Universidade de Brasília - UNB, Brasília/DF, [2007]. 
AMARAL, Wagner Roberto; FARIA, Tânia Maria Baibich. A presença dos estudantes indígenas nas universidades estaduais do Paraná: trajetórias e pertencimentos. Estudos RBEP, Brasília, v. 93, n. 235, p. 818-835, set./dez. 2012.

APOLINÁRIO, Juciene Ricarte. Povos Timbira: territorilização e a construção de práticas políticas nos cenários coloniais. Revista de História, São Paulo, n. 168, p. 244$270,2013$.

ARIÈS, Philippe. História social da criança e da família. Rio de Janeiro: Guanabara, 1978.

ASSOCIAÇÃO Nacional dos Dirigentes das Instituições Federais de Ensino Superior. Perfil Socioeconômico e Cultural dos Estudantes de Graduação das Universidades Federais Brasileiras. Fórum Nacional de Pró-Reitores de Assuntos Comunitários e Estudantis (FONAPRACE), 2011. Disponível em: http://www.andifes.org.br/index.php?option=com_docman\&task=cat_view\&gid=240\&I temid=27 . Acesso em: 11 mar. 2016.

BORBA, Telêmaco. Actualidade indígena (Paraná, Brazil). Curitiba: Impressora Paranaense, 1908.

BRASIL. Constituição da República Federativa 1988. Brasília: Coordenação de Publicações, 2002.

BUZATTO, Marline Dassoler; PELIZZARI, Diego J.; BUZATTO, Cleber C. A saga do povo Xetá no Paraná. Curitiba: Conselho Indigenista Missionário, 2015. Disponível em: http://www.cimi.org.br/site/pt-br/?system=news\&action=read\&id=2790 ..Acesso em: 13 dez. 2015.

CIMBAluK, Lucas. A Criação da Aldeia Água Branca na Terra Indígena Kaingang Apucaraninha: "Política Interna", Moralidade e Cultura. 2013. 252 f. Dissertação (Mestrado em Antropologia Social) - PPCHLA, UFP, Curitiba, PR, [2013].

COHN, Clarice. Culturas em transformação: os índios e a civilização. Perspectiva, São Paulo, p. 36- 42, 2001.

A cultura nas escolas indígenas. In: CARNEIRO DA CUNHA, Manuela; NIEMEYER CESARINO, Pedro (Org.). Políticas culturais e povos indígenas. São Paulo: Unesp, 2014. p. 313-336.

CUNHA, Manuela Carneiro. Os direitos do índio: ensaios e documentos. São Paulo: Brasiliense, 1987.

O futuro da questão indígena. In: LOPES DA SILVA, Aracy; GRUPIONI, Luís Donizete Benzi (Org.). A temática indígena na escola: novos subsídios para professores de $1^{\circ} \mathrm{e} 2^{\circ}$. Brasília: MEC/MA- RI/UNESCO, 1995. p. 121-136. 
2012.

Índios no Brasil: História, Direitos e Cidadania. São Paulo: Claro Enigma,

D’ ANGELIS, Wilmar R.; VEIGA. Juracilda. Habitação e Acampamentos Kaingang hoje e no passado. Revista Cadernos do CEOM, n. 18, p. 213-242, 2003.

FOUCAULT, Michel. Vigiar e punir: nascimento da prisão. Petrópolis: Vozes, 1987.

FREIRE, José Ribamar Bessa; MALHEIROS, Márcia Fernanda. Aldeamentos Indígenas no Rio de Janeiro. Rio de Janeiro: UERJ, 2010.

FUNAI - Fundação Nacional do Índio. Quem são. Índios no Brasil. 2016. Disponível em: http://www.funai.gov.br/index.php/indios-no-brasil/quem-sao?limitstart=0\# Acesso em: 29 mar. 2016.

GALLOIS, Dominique Tilkin. A escola como problema: algumas posições. In: CARNEIRO DA CUNHA, Manuela; NIEMEYER CESARINO, Pedro (Org.). Políticas culturais e povos indígenas. São Paulo: Unesp, 2014. p. 509-517.

LÉVI-STRAUSS, Claude. Tristes Trópicos. São Paulo: Schwarcz S.A., 2014.

LONDRINA. Prefeitura Municipal. Programa de atendimento à Comunidade Kaingang da terra indígena do Apucaraninha. 2016. Disponível em: http://www.londrina.pr.gov.br/index.php?option=com_content \&view=frontpageplus\&It emid=178 . Acesso em: 18 mar. 2016.

LOPES DA SILVA, Aracy; NUNES, Ângela; MACEDO, Ana Vera Lopes da Silva (Org.). Crianças indígenas: ensaios antropológicos. São Paulo: Global, 2002.

LUCIANO, Gersem dos Santos. Educação indígena. In: O Índio Brasileiro: o que você precisa saber sobre os povos indígenas no Brasil de hoje. Brasília: Ministério da Educação, Secretaria de Educação Continuada, Alfabetização e Diversidade, 2006. p. 128-169.

Os povos indígenas do Alto Rio Negro e a escola. In: Educação para manejo do mundo: entre escola ideal e a escola real no Alto Rio Negro. Rio de Janeiro: Contracapa/Laced, 2013. p. 73-95.

LUCKMANN, Sandro. Educação escolar indígena na terra indígena guarita: um olhar sobre a trajetória missionária indigenista da IECLB e COMIN. 2011. 155 f. Dissertação (Mestrado em Educação nas Ciências) - PPGEC, URNERGS, Ijuí, RS, [2011].

MATO, Daniel. Instituciones interculturales de educación superior en América Latina: panorama regional, procesos interculturales de construcción institucional, logros, dificultades, innovaciones y desafíos. In: . MATO, Daniel (Org.). Instituciones Interculturales de Educación Superior en América Latina: procesos de 
construcción. Logros, Innovaciones y Desafíos. Caracas: IESALC-UNESCO, 2009. p. $13-78$.

MONTEIRO, John Manuel. O desafio da história indígena no Brasil. In: LOPES DA SILVA, Aracy; GRUPIONI, Luís Donizete Benzi (Org.). A temática indígena na escola: novos subsídios para professores de $1^{\circ} \mathrm{e} 2^{\circ}$. Brasília: MEC/MA- RI/UNESCO, 1995. p. 23-26.

MOTA, Lúcio Tadeu. A Guerra de Conquista nos Territórios dos Índios Kaingang do Tibagi. In: Encontro Regional de História, 5. 1996, Ponta Grossa, Anais... Ponta Grossa: ANPUH, 1996.

As guerras dos índios Kaingang: a história épica dos índios Kaingang no Paraná (1769-1924). Maringá: Eduem, 2008.

NUNES, Ângela. No tempo e no espaço: brincadeiras das crianças A'uwẽ-Xavante. In: SILVA, Aracy Lopes; MACEDO, Ana Vera Lopes da Silva; NUNES, Ângela (Org.). Crianças indígenas: ensaios antropológicos. São Paulo: FAPESP/Global/MARI, 2002. p. 64-99. (Série Antropologia e Educação).

OLIVEIRA, João Pacheco de. Uma Etnologia dos “Índios Misturados"? Situação Colonial, Territorilização e Fluxos Culturais. Mana, Rio de Janeiro, v. 4, n. 1, p. 47-77, 1998.

A economia cafeeira no Paraná até a década de 1970. Revista Vitrine da Conjuntura, Curitiba, v. 2, n. 4, p. 1-8, 2009.

PANKARARU, Maria das Dores de Oliveira. As políticas públicas de Educação Superior para indígenas e afrodescendentes no Brasil: perspectivas e desafios. In: MATO, Daniel Mato (Org.). Educación Superior y Pueblos indígenas y Afrodescendientes en América Latina: Normas, Políticas y Prácticas. Caracas: IESALC-UNESCO, 2012. p. 177-210.

PARANÁ. Governo do Estado. Catálogo seletivo de documentos referentes aos indígenas no Paraná provincial: 1871 - 1892. Curitiba, 2009.

PARENTE, Regina Marques; MATTIOLI, Érica Aparecida Kawakami; MANCUSO, Maria Inês Rauter. Educação para as relações étnicos-raciais na perspectiva dos Direitos Humanos. In: SILVÉRIO, Valter Roberto; MATTIOLI, Érica Aparecida Kawakami; MADEIRA, Thais Fernanda Leite (Org.). Relações étnico-raciais: um percurso para educadores. São Carlos, 2013.p. 175.

PAULINO, Marcos Moreira. Povos indígenas e ações afirmativas: o caso do Paraná. 2008. 162 f. Dissertação (Mestrado em Educação) - PPGE, UFRJ, Rio de Janeiro, RJ, [2008]. 
PLANO NACIONAL DE EDUCAÇÃO. 9. Educação Indígena. 2001. Disponível em: http://www.planalto.gov.br/ccivil_03/leis/leis_2001/110172.htm . Acesso em: $10 \mathrm{jul}$. 2016.

REBOLLEDO, Nicanor. Cultura, escolarización y etnografía: los Palikur en el amazonas brasileño del Bajo Uaça. Universidad Iberoamericana. 2011. Disponível em: $<$ https://books.google.com.br/books?id=U0MEQYyiyi4C\&pg=PP4\&lpg=PP4\&dq=Cult ura,+escolarizaci\% C3\%B3n+y+etnograf\%C3\%ADa+rebolledo\&source=bl\&ots=Numg bBp2ad\&sig=rk_BYzCN8UB5MON2AFnfNwIAFT8\&hl=pt-

BR\&sa $=X \& v e d=0 \mathrm{CBwQ6AEwAGoVChMIh9S1nduEyQIVQ4KQCh1bdgh0 \# v=onepa}$ ge\&q=Cultura\%2C\%20escolarizaci\%C3\%B3n\%20y\%20etnograf\%C3\%ADa\%20reboll edo\&f=false $>$ Acesso em: 09 nov. 2011.

RIBEIRO, Darcy. Os índios e a civilização: a integração das populações indígenas no Brasil moderno. São Paulo: Companhia das letras, 1996. p. 254-262.

RICARDO, Carlos Alberto. "Os índios" e a sociodiversidade nativa contemporânea no Brasil. In: LOPES DA SILVA, Aracy; GRUPIONI, Luís Donizete Benzi (Org.). A temática indígena na escola: novos subsídios para professores de $1^{\circ} \mathrm{e} 2^{\circ}$. Brasília: MEC/MA- RI/UNESCO, 1995. p. 29-59.

SECRETARIA de Educação Profissional e Tecnológica do Ministério da Educação SETEC/MEC. Perspectivas da educação Profissional técnica de nível médio: Proposta de Diretrizes Curriculares Nacionais. São Paulo: Editora Moderna Ltda., 2012. p. 38.

SILVA, André Luiz. Grupo MARI: Educação e respeito à diversidade Brasileira. Cadernos de Campo, São Paulo, n. 4. p. 193-196, 1994.

SUCHANEK, Marcia Gómes O. Povos Indígenas no Brasil: de Escravos à Tutelados, Uma Difícil Reconquista da Liberdade. Revista Confluências, Niterói, v. 12, n. 1, p. 240-274, 2012.

TASSINARI, Antonella Maria Imperatriz. A educação escolar indígena no contexto da antropologia brasileira. Ilha, Florianópolis, v. 10, n. 1, p. 218-243, nov. 2008.

TEIXEIRA, Gercilene. Reflexões acerca da pureza cultural indígena. Ambiente Brasil. 2015.2 Disponível em: http://ambientes.ambientebrasil.com.br/indios/artigos/reflexoes_acerca_da_pureza_cult ural_indigena.html . Acesso em: 12 nov. 2015.

TOMMASINO, Kimiye. Os kaingang e os guarani no paraná: inimigos míticos no passado, aliados políticos no presente. 18a. Reunião da ABA/1992 - Belo Horizonte/MG, 12 a 15 de abril de 1992.

A ecologia dos Kaingang da bacia do rio Tibagi. In: MEDRI, Moacyr E. et al

(Org.). A bacia do rio Tibagi. Londrina, 2002.p. 81-100. 
A Educação Escolar Indígena no Paraná. Revista Mediações, Londrina, v. 8, n. 1, p. 71-98, jan./jun. 2003.

Os povos indígenas no Paraná: 500 anos de encobrimento. 2011. Disponível em: http://ktommasino.blogspot.com.br/2011/03/os-povos-indigenas-no-parana-500anos.html. Acesso em: 28 mar. 2016.

Diretrizes para a política de educação escolar indígena no Paraná: algumas considerações preliminares. In: D' ANGELIS, Wilmar, VEIGA, Juracilda (Org.). Leitura e escrita em escolas indígenas: encontro de educação escolar indígena no $10^{\circ}$ COLE - 1995. Campinas: COLE,1997. p. 113-136.

VANALI, Ana Crhistina O Botucudo tibagyano: analise sobre os registros etnográficos de Telêmaco Borba. Curitiba: Museu Paranaense, 2013. (Coleção Teses).

Recebido em: 30/07/2016 * Aprovado em: 09/10/2016 * Publicado em: 31/12/2016 